\title{
A influência grafo-fônico-fonológica na produção oral de multilíngues e o papel da proficiência: uma abordagem dinâmica*
}

\author{
Grapho-phonic-phonological influence in multilinguals' speech production and \\ the role of proficiency: a Dynamic approach \\ Cintia Avila Blank \\ Universidade Federal de Pelotas - Pelotas - Rio Grande do Sul - Brasil \\ Márcia Cristina Zimmer \\ Centro Universitário Ritter dos Reis - Porto Alegre - Rio Grande do Sul - Brasil \\ $\diamond$
}

\begin{abstract}
Resumo: Este estudo analisa a transferência de padrões grafêmicos e fonético-fonológicos durante a produção de vogais em multilíngues, considerando a proficiência linguística nesse processo. Para tanto, 5 homens, falantes de português brasileiro como L1, de espanhol como L2 e de inglês como L3 participaram desta pesquisa. Suas proficiências foram avaliadas com a aplicação de testes reconhecidos, a partir dos quais foi possível classificá-los como avançados em espanhol (L2) e intermediários em inglês (L3). Os participantes ainda realizaram 3 testes de leitura oral de palavras, um em cada uma de suas línguas. A tarefa pedia que os participantes lessem frases-veículo, nas quais havia palavras-alvo de alta frequência. As vogais dos participantes foram medidas - F1, F2 e duração - com o uso do programa Praat. As vogais produzidas pelos multilíngues foram comparadas, considerando suas similaridades ortográficas e fonético-fonológicas. Os resultados encontrados são discutidos de acordo com a abordagem da Teoria dos Sistemas Dinâmicos.
\end{abstract}

Palavras-chave: Multilinguismo; Influência grafo-fônico-fonológica; Proficiência linguística, Produção de vogais orais

\begin{abstract}
This study aims to look into multilinguals' transfer of graphemic and phoneticphonological patterns during vowel production, taken the role of proficiency in this process. For that purpose, 5 male multilingual speakers of Brazilian Portuguese (L1), Spanish (L2) and English (L3) participated in the study. Their proficiency levels were assessed by validated tests, and they were found to be advanced in Spanish (L2) and intermediate in English (L3). The participants also took part in three reading aloud tasks, one in each language. In each task, they were asked to read carrier sentences (say word), in which the words were high frequency. The participants' vowels were measured - F1, F2, and duration values - in the software Praat. The vowels produced by the multilingual participants in each language were compared, considering their orthographic and phonetic-phonological similarities. The findings are discussed in the perspective of the Dynamic Systems Theory.
\end{abstract}

Keywords: Multilingualism; Grapho-phonic-phonological influence; Linguistic proficiency; Oral vowel's production

* A pesquisa foi aprovada pelo Comitê de Ética em Pesquisa da UCPel, com número de protocolo 2011/75. 


\section{Introdução}

Para os estudos em aquisição da linguagem, o bilinguismo é tema de pesquisa extremamente estudado, sendo muitas as abordagens teóricas e os resultados empíricos a que se tem acesso atualmente. Entretanto, cada vez mais estudos têm voltado sua atenção também para o desenvolvimento de pesquisas teóricas e aplicadas que investigam o caso de indivíduos que aprenderam, além de sua língua materna, duas ou mais línguas estrangeiras, sendo considerados multilíngues. A aquisição multilíngue, por sua vez, é considerada como a aquisição de outras línguas que não a L1 e a primeira língua estrangeira (L2) aprendida por um indivíduo (CENOZ, 2000).

$\mathrm{O}$ desenvolvimento de pesquisas no âmbito do multilinguismo apresenta grande complexidade, uma vez que o maior conhecimento linguístico dos participantes leva a uma maior dificuldade para a interpretação dos resultados obtidos nas pesquisas, considerando-se que existe um número maior de aspectos linguísticos cujos padrões podem ser transferidos entre si, dependendo da intensidade com que cada língua é usada e estudada. Nesse sentido, é importante levar em consideração um enfoque teórico que aborde os resultados dessas pesquisas, considerando a complexidade inerente à condição multilíngue. Por isso, ao lançar-se um estudo sobre a influência grafo-fônico-fonológica na produção oral em multilíngues, buscou-se seguir a abordagem dinâmica de aquisição da linguagem, que sustenta a premissa de que o conhecimento linguístico faz parte de um sistema interativo que é suscetível a mudanças através do tempo (VAN GELDER; PORT, 1995, KELSO, 1995, ALBANO, 2012). Assim, a influência interlinguística pode ser entendida como um fenômeno intrinsecamente relacionado à condição multilíngue, uma vez que as línguas e padrões linguísticos são vistos como ativados de forma concomitante (DE BOT et al., 2005).

O presente artigo tem por objetivo investigar como a produção de vogais orais em L1 (português), L2 (espanhol) e L3 (inglês) por multilíngues é mutuamente influenciada em função da proficiência linguística e das características grafo-fônico-fonológicas de cada uma dessas línguas. Para tanto, foram selecionados 5 participantes multilíngues do sexo masculino, que realizaram 2 testes de proficiência, um para cada língua estrangeira que conheciam, e 3 testes de produção oral de vogais, um para cada língua falada por eles. Com a realização dos testes de produção oral, foi possível analisar as características acústicas (F1, F2 e duração) em cada língua estudada, o que possibilitou estabelecer como a produção oral dos multilíngues para as vogais orais das 3 línguas está associada.

Para apresentar a pesquisa ora proposta, este trabalho está dividido em quatro seções principais, que abordam a visão dinâmica de influência grafo-fônico-fonológica esposada neste trabalho, os critérios metodológicos aplicados à pesquisa, a descrição e a discussão dos resultados e, por fim, apresentam uma síntese das principais conclusões a que se chegou com esta pesquisa.

\section{A visão dinâmica de influência grafo-fônico-fonológica na produção oral de multilíngues}

Ao pensar a aquisição multilíngue partindo-se do princípio de que essa aquisição funciona como um sistema dinâmico, em que línguas e sistema cognitivo processam padrões de maneira integrada e indissociável, várias interpretações podem ser feitas e conduzidas, com o intuito de reformular as noções tradicionais que permeiam o campo de aquisição de línguas.

Van Gelder e Port (1995) descrevem os sistemas dinâmicos como sistemas com estados que mudam através do tempo. Para os autores, um sistema dinâmico deve ser pensado como um conjunto de espaço de estados possíveis em conjunto com regras evolutivas que determinam sequências de pontos nesse espaço (VAN GELDER; PORT, 1995).

Albano (2012) explica que a noção de sistema dinâmico está atrelada à construção de uma teoria geral dos sistemas que passam de um estado a outro, no tempo, obedecendo a uma determinada regra, mesmo que haja aleatoriedade nesse processo. Alguns exemplos de sistemas dinâmicos que a autora fornece correspondem ao movimento pendular ou de um satélite, por exemplo.

Para a Teoria dos Sistemas Dinâmicos, é importante a ideia de que os elementos de um sistema sempre interagem uns com os outros. Para Van Gelder e Port (1995), a maneira como um elemento muda dentro do sistema depende diretamente da forma como se apresentam os demais elementos. Assim, um conjunto de elementos de um sistema deve ser interativo e autocontido, o que significa dizer, então, que a mudança em qualquer elemento do sistema depende exclusivamente do estado de outros elementos no conjunto (VAN GELDER; PORT, 1995).

À diferença de um sistema estático, um sistema dinâmico possui propriedades que podem variar tanto em função do tempo quanto em função do espaço. Num sistema dinâmico, alguns pontos no espaço, ou seja, alguns subconjuntos no espaço costumam ser mais preferidos do que outros. Essa possibilidade que os sistemas dinâmicos possuem de estabelecerem-se em determinados pontos caracteriza, na teoria dinâmica, a noção de atratores.

Ao discorrer sobre a noção de atrator, Albano (2012) ilustra o seu conceito, explicando o movimento de um 
pêndulo real, que estaria sujeito a atrito e que possuiria um atrator pontual, que é seu ponto de repouso. Nesse sentido, o estado atrator seria classificado como um comportamento estável e categórico, ocorrendo num sistema instável, como o pendular.

Voltando-se para a linguística, Albano (2012) dá exemplos de como o conhecimento fonético-fonológico pode funcionar como um atrator. Segundo a autora, as trajetórias especificadas para as variantes de /e/ e de /i/ podem ser dadas pelo grau de constrição do trato vocal. Nessa direção, o grau de abertura necessário para a realização do gesto articulatório de /e/ é considerado maior do que aquele necessário para a realização de /i/, embora possa haver uma dispersão ou sobreposição na realização desses dois alvos. Por isso, Albano (2012) sustenta que os alvos de /e/ e de /i/ devem ser entendidos como atratores naturais no espaço de estados especificado para a dimensão fonética de abertura.

Zimmer e Alves (2012) também entendem a linguagem como um sistema dinâmico que sofre a influência de atratores. Para os autores, quando um aprendiz de L2 ainda tem pouca fluência, o sistema dinâmico da L1, que está equipado com atratores típicos dessa língua, atua sobre o sistema da L2, modificando a dinâmica da tarefa na produção em língua estrangeira. Isso leva ao enviesamento dos atratores típicos da L2 no espaço de estados articulatórios do falante bilíngue, causando um sotaque perceptível na fala. Por outro lado, os autores explicam que, em falantes com proficiência elevada em sua L2, mais especificamente em falantes proficientes que tiveram a oportunidade de usar sua língua estrangeira em contexto de imersão, espera-se que seu sistema de produção da fala esteja sintonizado com o sistema da L2. De acordo com Zimmer e Alves (2012), nesses casos, a fala em língua materna pode começar a seguir uma orquestração gestual conforme a configuração dos atratores dos padrões da L2, em decorrência da imersão.

Um dos modelos teóricos que buscam explicar a produção oral por meio da Teoria dos Sistemas Dinâmicos foi proposto por Albano (2009), que desenvolveu a Fonologia Gestual, segundo a qual os articuladores da fala devem ser entendidos como osciladores. Segundo Raposo de Medeiros (2012), a Fonologia Gestual atual entende que o gesto articulatório é um sistema dinâmico por natureza, estando ligado a um oscilador não-linear de planejamento. Conforme frisa a autora, um oscilador não trabalha sozinho. Ele está, portanto, ligado a outro oscilador que, por sua vez, está relacionado a outro gesto. Os osciladores estabelecem relações de faseamento entre si, que correspondem aos modos com que os osciladores se acoplam ao mundo físico. Nesse sentido, o acoplamento pode-se dar de duas formas: em fase ou em antifase. Segundo Goldstein et al. (2007), percebe-se, por exemplo, que as sílabas CV demonstram uma preferência de acoplamento em fase, ao passo que as sílabas VC demonstram uma preferência de acoplamento em antifase. É importante, pois, referir que o grande destaque da Fonologia Gestual é a concepção de múltiplos gestos, ou osciladores, que entram em sintonia com o ambiente.

Partindo-se, então, de um arcabouço teórico dinâmico, e buscando situar a relação entre conhecimento grafêmico e fonético-fonológico nessa visão, o estudo da transferência grafo-fônico-fonológica proposto neste trabalho deve partir do pressuposto de que o processamento da leitura de inputs grafêmicos deve estar associado intrinsecamente à ativação fonético-fonológica que tais inputs demandarão. Nessa direção, o conhecimento da correspondência grafo-fônico-fonológica de uma língua estará ativado durante a leitura em outra língua qualquer, já que esses padrões linguísticos são acessados de forma paralela, sendo essa correspondência entre inputs escritos e representação fonético-fonológica de natureza cognitiva (ZIMMER, 2004; MACWHINNEY, 2002). Essa ativação em paralelo levará à competição entre os diferentes padrões entre as línguas, de forma que o padrão ativado com mais frequência tenderá a sobrepujar os demais (MACWHINNEY, 2002).

Tendo-se apresentado a visão dinâmica de aquisição da linguagem seguida neste trabalho, e, mais especificamente, a visão dinâmica de conhecimento fonético-fonológico, passa-se, a seguir, à apresentação da metodologia aplicada.

\section{Pesquisa empírica}

Em consonância com a revisão da literatura, esta pesquisa tem como objetivo geral investigar como a produção de vogais orais em L1 (português), L2 (espanhol) e L3 (inglês) por multilíngues é mutuamente influenciada em função da proficiência linguística e das características grafo-fônico-fonológicas de cada uma dessas línguas. A hipótese traçada para esse objetivo era a de que o grau de proficiência dos multilíngues em cada uma de suas línguas influência os padrões grafo-fônico-fonológicos das vogais orais entre as três línguas. Assim, espera-se que as línguas mais proficientes sejam mais notadas na produção das línguas menos proficientes. Esse resultado é esperado, uma vez que, partindo-se de uma abordagem dinâmica para as línguas, espera-se que os padrões grafofônico-fonológicos das línguas mais proficientes atuem como atratores mais fortes durante a produção de leitura oral (DE BOT, 2004; ZIMMER, 2004; ALBANO, 2012; ZIMMER; ALVES, 2012). Para responder ao objetivo e à hipótese traçada, as vogais orais das 3 línguas em estudo foram analisadas no que diz respeito às suas características acústicas (F1, F2 e duração). 


\section{Método}

A investigação empírica foi do tipo pesquisa experimental, realizada com 5 participantes do sexo masculino, de forma transversal. Os participantes apresentavam idade média de 25 anos, sendo todos residentes na cidade de Pelotas, Rio Grande do Sul (Brasil). Dos 5 participantes, 3 possuíam ensino superior completo e 2 ainda eram estudantes de cursos de graduação. Todos os participantes realizaram testes de proficiência validados internacionalmente em suas línguas estrangeiras (DELE, para o espanhol, e TOEIC, para o inglês), sendo classificados como altamente proficientes em espanhol e intermediários em inglês. Os participantes da pesquisa ainda responderam a uma entrevista para aferição de seus conhecimentos e experiências linguísticas e assinaram um Termo de Consentimento Livre e Esclarecido, que apresentava detalhadamente cada uma das etapas da pesquisa.

\section{Instrumentos da pesquisa}

Para a obtenção dos valores de F1, F2 e duração das vogais orais das três línguas faladas pelos participantes investigados nesta pesquisa foram aplicados 3 testes de leitura oral de palavras, um para cada língua falada pelos participantes. As palavras utilizadas nos experimentos foram extraídas de corpora $^{1}$ linguísticos, sendo consideradas de alta frequência. Como se optou por analisar as vogais orais das três línguas, todas as palavras selecionadas apresentavam essas vogais em posição tônica, inseridas em frases-veículo (diga bota, diga codo, say dog). Em cada um dos experimentos, cada vogal oral foi apresentada em 5 palavras diferentes, sendo que cada palavra apresentada foi repetida 5 vezes, gerando, por participante, um total de 25 repetições para cada vogal em cada língua. Contabilizando os dados produzidos pelos 5 participantes da pesquisa, foi obtida, para a língua portuguesa, a produção total de 875 vogais ( 7 vogais $\times 5$ palavras $\times 5$ repetições $\times 5$ participantes). Para a língua espanhola, foram analisadas 625 vogais ( 5 vogais $\times 5$ palavras $\times 5$ repetições $\times 5$ participantes). Já para a língua inglesa, foi analisado um total de 1.225 vogais ( 9 vogais $\times 5$ palavras $\times 5$ repetições $\times 5$ participantes $)$. A apresentação dos itens lexicais de cada experimento aos participantes foi feita de forma aleatória. A aplicação dos testes de leitura de palavras em cada uma das 3 línguas foi feito em dias diferentes, para que não houvesse a influência direta da leitura de uma língua sobre outra.

\footnotetext{
Para a língua portuguesa, foi usado o corpus Ceten-Folha. Para a língua espanhola, foi usado o corpus del Español. Já para a língua inglesa, foi usado o corpus Brown. As palavras selecionadas tinham frequência mínima de 1000 nos corpora pesquisados.
}

\section{Levantamento e computação dos dados}

As vogais orais das três línguas estudadas foram analisadas por meio do programa Praat, o que possibilitou que se extraíssem os dados de F1, F2 e duração de cada vogal de cada língua. A partir disso, os dados foram tratados estatisticamente com o uso do programa SPSS. Foi realizada a estatística descritiva dos dados e foi aplicado o teste de Friedman com correção de Bonferroni para que se pudesse calcular se a diferença entre as vogais das três línguas analisadas era significativa $(p=, 017)$, seja para F1, F2 ou duração. Encontrando-se resultados de diferenças significativas entre as vogais comparadas, partia-se do pressuposto de que essas vogais foram produzidas pelos participantes de forma diferenciada. Por outro lado, se as vogais comparadas não apresentassem diferenças estatísticas significativas, entendia-se que essas vogais tinham sido produzidas de maneira semelhante entre as línguas comparadas. As vogais foram comparadas em grupos de 3, sendo que sempre eram comparadas vogais de línguas diferentes, que apresentassem algum tipo de semelhança que pudesse ensejar algum tipo de transferência grafo-fônicofonológica. O Quadro 1 apresenta as vogais que foram comparadas entre as línguas.

Quadro 1 - Vogais analisadas em cada língua para o experimento de produção de vogais

\begin{tabular}{|l|c|c|c|}
\hline & Português & Espanhol & Inglês \\
\hline Vogais & $\mathrm{a}$ & $\mathrm{a}$ & $\mathrm{a}$ \\
& $\mathrm{e}$ & $\mathrm{e}$ & $\wedge$ \\
$\varepsilon$ & $\mathrm{i}$ & $æ$ \\
& $\mathrm{i}$ & 0 & $\varepsilon$ \\
$\mathrm{o}$ & $\mathrm{u}$ & $\mathrm{i}$ \\
& $\mathrm{u}$ & & $\mathrm{I}$ \\
& $\mathrm{u}$ & & $\mathrm{U}$ \\
& & & $\mathrm{u}$ \\
& & & $\mathrm{J}$ \\
\hline
\end{tabular}

\section{Descrição e discussão dos resultados}

Após a medição das vogais orais de cada língua através do software Praat, os dados formânticos (F1 e F2) e de duração de cada vogal medida foram organizados para a realização da análise estatística, que foi realizada com o auxílio do software SPSS. Ao observarem-se os resultados das comparações realizadas entre as vogais das três línguas no que diz respeito, primeiramente, à altura $(\mathrm{F} 1)$ com que as vogais foram produzidas, descobriu-se que as seguintes comparações de valores de F1 apresentaram resultados de diferença que não foram significativos na análise estatística, evidenciando uma maior associação entre essas vogais: /e/ do português e 
/e/ do espanhol $(Z=-1,322, p>, 017) ; / 0 /$ do português e /o/ do espanhol $(\mathrm{Z}=-2,165, p>, 017) ; / \mathrm{u} /$ do português e $/ \mathrm{u} /$ do espanhol $(\mathrm{Z}=-1,219, p>, 017) ; / \mathrm{u} /$ do português e $/ \mathrm{u} /$ do inglês $(Z=-, 464, p>, 017) ; \mathrm{e} / \mathrm{u} /$ do português e $/ \mathrm{v} /$ do inglês $(Z=-, 977, p>, 017)$. Esses resultados apontam para uma maior associação entre esses pares de vogais em relação à altura com que foram produzidos.

Para a análise do posicionamento no eixo anteroposterior (F2), a aplicação dos testes estatísticos evidenciou não haver diferenças significativas entre as vogais /i/ do português, /i/ do espanhol e /I/ do inglês $(\mathrm{Z}=2,253, p>, 017)$, /a/ do espanhol e /a/ do inglês $(\mathrm{Z}=-2,109, p>, 017) ; / \mathrm{a} /$ do português e $/ \Lambda /$ do inglês $(\mathrm{Z}=-, 740, p>, 017) ; / \mathrm{e} /$ do português e /e/ do espanhol ( $Z=-1,623, p>, 017) ; / \mathrm{o} /$ do português e / / / do inglês $(Z=-1,858, p>, 017) ; / \mathrm{o} /$ do português e $/ \mathrm{o} /$ do inglês $(\mathrm{Z}=-2,008, p>, 017) ; / \mathrm{u} /$ do português e $/ \mathrm{u} /$ do inglês $(\mathrm{Z}=-, 073, p>, 017) ; \mathrm{u} /$ do português e $/ \mathrm{v} /$ do inglês $(\mathrm{Z}=-, 048, p>, 017) ; / \mathrm{i} /$ do português e /i/ do espanhol $(\mathrm{Z}=-1,740, p>, 017) ; \mathrm{e} / \mathrm{i} / \mathrm{do}$ português e /I/ do inglês $(\mathrm{Z}=-, 871, p>, 017)$.

As vogais das três línguas analisadas nesta parte da pesquisa ainda foram comparadas com relação à medida de duração. Com a aplicação dos testes estatísticos verificou-se que não havia diferenças significativas entre os seguintes pares: /a/ do português e /a/ do espanhol $(\mathrm{Z}=-1,826, p>, 017) \mathrm{e} / \mathrm{u} /$ do português e $/ \mathrm{u} /$ do espanhol $(\mathrm{Z}=-, 663, p>, 017)$, que foram produzidos de forma mais semelhante.

Com o fim de generalizar os resultados encontrados, o Quadro 2 apresenta os pares de vogais comparados em que não se constatou uma diferença significativa, seja para F1, F2 ou duração. Esses resultados indicam uma maior aproximação na produção entre as vogais das línguas comparadas.

Quadro 2 - Síntese das vogais que apresentaram valores de F1, F2 ou duração próximos entre línguas diferentes.

\begin{tabular}{|c|c|c|c|}
\hline Pares de vogais & F1 & F2 & Duração \\
\hline /a/ PORT - /a/ ESP & & & $X$ \\
\hline /e/ PORT - /e/ ESP & $X$ & $X$ & \\
\hline /o/ PORT - /o/ ESP & $X$ & & \\
\hline /u/ PORT - /u/ ESP & $X$ & & $X$ \\
\hline /i/ PORT - /// ESP & & $X$ & \\
\hline /u/ PORT - /u/ ING & $X$ & $X$ & \\
\hline /u/ PORT - /v/ ING & $X$ & $X$ & \\
\hline /i/ PORT - /I/ ING & & $X$ & \\
\hline /a/ PORT - /N/ ING & & $X$ & \\
\hline /o/ PORT - /o/ ING & & $X$ & \\
\hline /o/ PORT - /o/ ING & & $X$ & \\
\hline /a/ ESP - /a/ ING & & $X$ & \\
\hline
\end{tabular}

A plotagem das médias de F1 e F2 encontradas para as vogais das três línguas produzidas pelos multilíngues pode ser usada como recurso para a visualização de cada vogal no espaço acústico (Fig. 1).

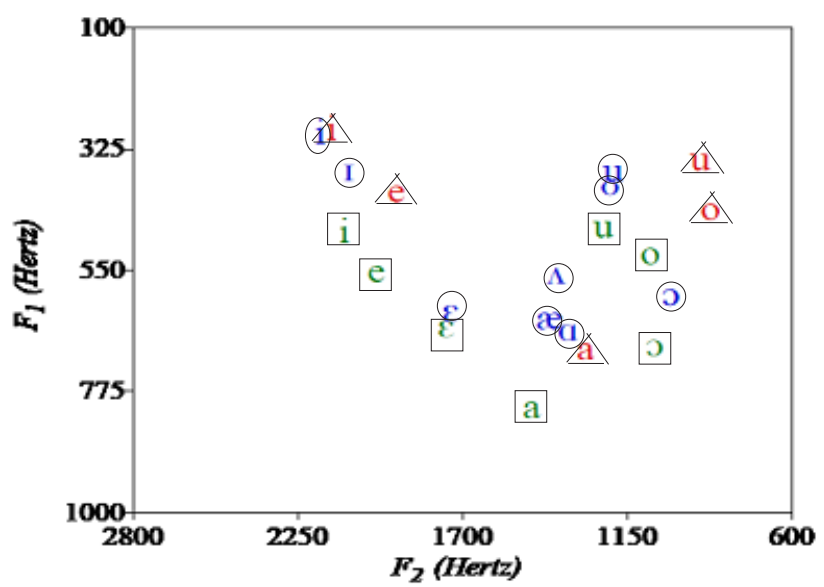

Figura 1 - Plotagem das médias de F1 e F2 das vogais produzidas pelos multilíngues em suas três línguas. As vogais do português são apresentadas em quadrados; as vogais do espanhol em triângulos; e as vogais do inglês em círculos.

Com o auxílio das informações sintetizadas no Quadro 2, e com a visualização da Figura 1, verificou-se que as vogais que mais se assemelharam entre si pertenciam à $\mathrm{L} 1$ e à $\mathrm{L} 2$ ou à $\mathrm{L} 1 \mathrm{e}$ à $\mathrm{L} 3$ dos multilíngues. As comparações feitas entre a L2 e a L3 dos multilíngues apresentaram diferenças significativas de produção para quase todos os pares de vogais, com exceção apenas para uma comparação, envolvendo a posição no eixo anteroposterior das vogais /a/ do espanhol e /a/ do inglês.

Nesses termos, percebe-se a presença da língua materna dos multilíngues associada ora ao espanhol, ora ao inglês, dependendo das vogais comparadas entre as línguas. Tem-se, então, a língua mais proficiente dos multilíngues sendo associada tanto a uma língua em que possuem um grau considerado elevado de proficiência (L2), quanto a uma língua em que possuem um grau intermediário de proficiência (L3).

Como não foram encontradas associações mais evidentes entre L2 e L3 na produção dos multilíngues, entende-se que a proficiência oral que possuem em sua L2 não foi suficiente para influenciar de forma mais notável a produção em L3, língua menos proficiente. Por outro lado, a língua materna dos participantes, cuja proficiência deve ser incontestável, aparece associada às demais línguas dos participantes da pesquisa, independente do grau de proficiência observado nessas línguas. Assim, parece correto afirmar que as vogais da L2 e da L3 dos multilíngues que apresentam influências interlinguísticas estão associadas notadamente à L1 dos participantes. 
É importante referir que, ao se propor o estudo da influência grafo-fônico-fonológica em multilíngues, buscou-se seguir a hipótese de que as influências entre as línguas se dariam de acordo com a proficiência observada em cada uma delas. Nesse sentido, esperava-se que as línguas mais proficientes estivessem mais associadas àquelas cuja proficiência era considerada inferior. Os resultados observados nesta pesquisa parecem corroborar parcialmente essa hipótese, uma vez que se constatou uma forte associação entre as vogais da L1 e da L2 e da L1 e da L3. O conhecimento proficiente que os multilíngues possuem em sua L2, que também poderia ter sido associado à sua L3, língua menos proficiente, não gerou padrões significativos a ponto de influenciar a produção em outra língua. Em suma, contrariando a maioria das pesquisas em multilinguismo, este estudo aponta para o papel destacado da L1 na transferência tanto para a L2 quanto para a L3.

Considerando o referencial teórico adotado neste artigo, acredita-se que os resultados obtidos estão em consonância com uma visão dinâmica de aquisição da linguagem, uma vez que influências interlinguísticas foram identificadas nas produções orais dos multilíngues. Diante disso, pode-se defender um conhecimento linguístico de natureza interativa, estando os padrões das línguas adquiridas por um indivíduo ativados durante o uso de qualquer uma delas, de forma interconectada (DE BOT, 2004; LARSEN-FREEMAN, 2007). O efeito dessa interação entre as línguas sobre a produção oral, no entanto, depende da força dos atratores de cada uma dessas línguas. Nesse sentido, entende-se que a proficiência linguística atua como um estado atrator, tal como definido pela Teoria dos Sistemas Dinâmicos, de forma que a língua mais proficiente dos multilíngues (L1) gera estados atratores mais fortes, que influenciam de forma notável as línguas menos proficientes (L2 e L3), conforme foi constatado nos resultados aqui apresentados.

A observação de maiores associações entre as vogais do português com o espanhol e do português com o inglês parece indicar que os atratores da língua materna dos multilíngues analisados nesta pesquisa possuem maior força, fazendo com que menos energia seja necessária para a sua ativação. Em outras palavras, os padrões da língua materna parecem ser ativados de forma mais espontânea que os das demais línguas. Parece, contudo, que esse padrão de influência interlinguística em que a língua materna desempenha um papel preponderante pode estar atrelado ao fato de os multilíngues participantes desta parte da pesquisa usarem suas línguas estrangeiras apenas em contextos acadêmicos. Embora tenham desenvolvido proficiência considerada elevada (L2) ou intermediária (L3) em suas línguas estrangeiras, é possível que a força dos atratores para essas línguas ainda não seja tão significativa. No que diz respeito especificamente à língua espanhola, é importante mencionar que a forte semelhança entre esta língua com a L1 dos participantes pode ter gerado um efeito de inteligibilidade. Assim, a forte associação entre a L1 e a L2 observada através dos dados pode remeter ao fato de os multilíngues talvez não terem como objetivo falar em L2 de forma semelhante aos falantes nativos. Nesse sentido, é possível que o objetivo dos multilíngues seja apenas comunicar-se de forma inteligível em L2. Embora não seja possível confirmar essa interpretação na pesquisa ora realizada, julga-se importante sinalizar essa possibilidade.

É importante retomar a noção apresentada por Zimmer e Alves (2012), que explicam que bilíngues de baixa proficiência terão seus atratores da $\mathrm{L} 1$ atuando sobre os da L2, modificando a dinâmica da tarefa nessa língua. Por outro lado, bilíngues que possuam proficiência elevada na L2, e principalmente aqueles que tiveram a oportunidade de usar essa língua num contexto de imersão terão o seu sistema de produção da fala mais sintonizado com os padrões dessa L2. Como se pode verificar, a descrição do funcionamento dos atratores feita pelos autores parece estar em consonância com os resultados encontrados nesta pesquisa, já que parece ter havido um maior carreamento (entrainment) feito pelos atratores da L1 dos multilíngues durante a fala em inglês (L3), língua em que os participantes não possuíam uma proficiência elevada. Por outro lado, a alta proficiência em espanhol (L2) não foi suficiente para que essa língua tivesse seus atratores sintonizados aos da L3 dos participantes. Nesse sentido, concorda-se com Zimmer e Alves (2012), quando chamam a atenção para o papel da imersão para que os atratores de uma língua estrangeira atuem de forma mais significativa.

Ainda sobre o funcionamento dos atratores, é preciso ter em mente a posição de Silva (2007), para quem a produção oral de uma L2 será influenciada pelo conhecimento que o aprendiz possui sobre a sua L1. Para a autora, o aprendiz de línguas tende a sintonizar os gestos da fala não-nativa de forma semelhante a como esses gestos são faseados em língua nativa. Isso resulta na sobreposição de gestos durante uma determinada produção, levando a diferentes relações de faseamento entre eles. Da mesma forma como observado por Silva (2007) para os bilíngues, os resultados que apontam para a ocorrência de influências interlinguísticas encontrados nesta pesquisa parecem seguir esse mesmo padrão, em que a produção em L2 e em L3 dos multilíngues aparece sintonizada aos gestos da L1. Ainda de acordo com a autora, acredita-se também que essa sintonia leva à sobreposição de gestos articulatórios durante a produção oral.

Albano (2012) explica, na perspectiva da Fonologia Gestual, que dois osciladores em fase iniciam suas 
trajetórias ao mesmo tempo. Por outro lado, dois osciladores em antifase terão suas trajetórias sobrepostas, de modo que uma será iniciada quando a outra já estiver chegando à metade do percurso. Partindo disso, Albano (2012) também explica que dois osciladores acoplados têm suas vibrações indissociáveis, o que acaba afetando a frequência, a amplitude ou a fase desses osciladores. Esse fenômeno, conhecido como carreamento (entrainment), faz com que um oscilador seja conduzido na mesma sintonia ou sincronia daquele que o arrasta ou carreia (entrain). Essas informações trazidas por Albano são de suma importância para esta pesquisa, ainda mais quando a autora esclarece que o arrastamento de um oscilador pode ser parcial. Assim, haveria uma sincronia ou sintonia incompleta entre os osciladores envolvidos.

Considerando os resultados que apontam para influências interlinguísticas nas produções das vogais dos multilíngues, pode-se argumentar que essas influências devem-se ao funcionamento acoplado dos osciladores correspondentes às diferentes línguas. Ao apresentarem vibrações indissociáveis, o funcionamento desses osciladores possibilitou a observação de associações significativas entre as diferentes línguas. Nessa direção, entende-se que houve um acoplamento parcial entre os osciladores responsáveis pelas frequências de altura e localização antero-posterior no trato, assim como para a medida de duração das diferentes línguas (em menor grau). O acoplamento parcial é assumido aqui, uma vez que não se observou uma sintonia total dos três parâmetros analisados entre as vogais das diferentes línguas (F1, F2 e duração). Em outras palavras, nenhum par de vogal entre as línguas apresentou semelhanças tanto em F1, F2 e duração.

Uma análise das vogais produzidas de forma associada entre as línguas que leve em conta as suas características grafo-fônico-fonológicas demonstra que existe uma sincronia na produção de várias vogais da língua portuguesa e espanhola. A vogal/a/ das duas línguas apresentou similaridades quanto à duração. A vogal /e/ das duas línguas apresentou uma associação em termos de F1 e F2. Já a vogal/i/ das duas línguas foi mais associada em relação à F2. A vogal /o/ das duas línguas apresentou uma associação de F1. Por fim, as vogais /u/ do português e do espanhol apresentaram produções associadas para F1 e duração. Pensando-se nas características grafo-fônicofonológicas do português e do espanhol, seria provável imaginar um maior acoplamento entre os osciladores da L1 e da L2 para a produção dessas vogais, já que, embora existam diferenças qualitativas em suas produções entre as línguas, a produção esperada para os grafemas /a/, /e/, /i/,/o/ e /u/ nas duas línguas é bastante semelhante. Porém, os multilíngues parecem realizar alguma diferenciação na forma como as vogais são produzidas nas duas línguas, já que os osciladores de F1, F2 e duração para essas vogais não apresentaram uma sintonia significativa para todos os três parâmetros analisados. Assim, pode-se dizer que as vogais produzidas apresentam características que, por um lado, assemelham-se entre português e espanhol e, por outro, não guardam semelhanças significativas.

No que diz respeito às características grafo-fônicofonológicas da língua portuguesa e inglesa, deve-se reconhecer que existe menos equivalência entre as correspondências grafema-fonema dessas línguas. Notase, no entanto, algumas associações entre as vogais do português e do inglês. As vogais $/ \mathrm{a} / \mathrm{e} / \mathrm{\Lambda} /, / \mathrm{i} / \mathrm{e} / \mathrm{I} / \mathrm{,} / \mathrm{o} / \mathrm{e}$ $/ \mathrm{o} / \mathrm{e} / \mathrm{\rho} / \mathrm{e} / \mathrm{\rho} /$ do português e do inglês, respectivamente, aparecem associadas em relação à F2. Já a vogal /u/ das duas línguas apresentou uma associação tanto em F1 quanto em F2, assim como a vogal /u/ do português e / $/$ do inglês.

Ao analisar-se o posicionamento das vogais /a/ do português e $/ \Lambda /$ do inglês, percebe-se que a vogal da língua inglesa parece mais sincronizada à vogal da língua portuguesa no eixo antero-posterior. Uma análise das características grafo-fônico-fonológicas da vogal da língua inglesa indica que o input escrito dado no experimento para o som de / / é o grafema " $u$ ". Diante do exposto, deve-se ter em mente que os multilíngues têm conhecimento de outro mapeamento grafo-fônicofonológico para o grafema "u" na língua inglesa, diferente daquele que conhecem para a sua língua materna. Esse conhecimento, embora não sofra influências significativas da língua materna para altura e duração, parece estar em sintonia com os osciladores da L1 quando se considera a articulação mais anteriorizada da vogal $/ \Lambda /$. Com isso, o oscilador correspondente à frequência de F2 da vogal inglesa parece ser conduzido em sintonia correspondente ao oscilador da vogal /a/ da língua materna.

Com relação às vogais /i/ da língua portuguesa $\mathrm{e} / \mathrm{I} / \mathrm{da}$ língua inglesa, que ficaram mais associadas em relação à produção de $\mathrm{F} 2$, pode-se prever que essa associação pode ter sido influenciada pelas características grafo-fônicofonológicas das vogais dessas línguas, uma vez que os inputs apresentados para a vogal / / / da língua inglesa são grafados com o grafema "i”. Como a vogal /i/ da língua portuguesa também é grafada com o mesmo grafema, isso pode acabar reforçando algum tipo de associação entre as línguas, que foi evidenciada na produção mais próxima para essas vogais no eixo antero-posterior. Mais uma vez, nota-se um efeito de carreamento entre dois osciladores de línguas diferentes, que se apresentam em sintonia durante a articulação de vogais de línguas diferentes no eixo antero-posterior.

As vogais $/ 0 /$ e $/ 0 /$ e $/ 0 /$ e $/ 0 /$ do português e do inglês, respectivamente, também apresentaram proximidades significativas no eixo de F2. É preciso 
mencionar que a vogal / $/$ / da língua inglesa possui diferentes correspondências grafo-fônico-fonológicas, que nem sempre correspondem àquela conhecida pelos multilíngues na sua língua materna. Mesmo assim, os multilíngues parecem reconhecer de alguma forma essas correspondências grafema-fonema do inglês para essa vogal, uma vez que, por exemplo, palavras apresentando sequências grafêmicas como "au" e "ou" foram produzidas com características esperadas para $/ 0 /$. Porém, essa produção é aproximada da língua materna no eixo de F2, sendo a produção da vogal / $/$ / do inglês influenciada tanto pela vogal/o/ do português quanto pela vogal / / da mesma língua.

Quanto aos pares de vogais $/ \mathrm{u} / \mathrm{e} / \mathrm{u} / \mathrm{e} / \mathrm{u} / \mathrm{e} / \mathrm{v} / \mathrm{da}$ língua portuguesa e da língua inglesa, respectivamente, verificou-se uma associação entre as vogais tanto para F1 quanto para F2. Verificando as correspondências grafo-fônico-fonológicas das vogais da língua inglesa, observou-se que as palavras escolhidas para leitura em inglês apresentando as vogais $/ \mathrm{u} / \mathrm{e} / \mathrm{v} /$, em sua grande maioria, eram grafadas com a sequência de grafemas "oo". Tendo em vista que a produção dessa sequência pelos multilíngues corresponde ao que seria esperado para a produção de $/ \mathrm{u} /$, considera-se que eles reconhecem uma correspondência grafema-fonema diferente daquela que utilizam para a sua língua materna, quando devem ler a sequência de grafemas "oo" em língua inglesa. Porém, parece não ter havido diferenciação entre os pares $/ \mathrm{u} /$ e / / da língua inglesa, que foram produzidos de forma bastante associada, tanto em altura quanto em posição no eixo antero-posterior. As duas vogais da língua inglesa foram associadas de forma significativa à vogal $/ \mathrm{u} /$ da língua portuguesa, evidenciando que os osciladores de F1 e F2 para as vogais da língua inglesa são carreados conforme a sintonia e sincronia dos osciladores da L1.

A última influência interlinguística constatada entre as línguas envolve as vogais /a/ do espanhol e/a/ do inglês, que foram associadas em sua posição no eixo anteroposterior. Essa foi a única comparação entre línguas em que se pôde constatar uma associação significativa entre L2 e L3. Considerando as características grafofônico-fonológicas da língua inglesa, verifica-se que o input grafêmico dado para a vogal da língua inglesa no experimento de leitura oral de palavras foi o grafema "o". $\mathrm{O}$ fato de os multilíngues terem conseguido pronunciar as palavras-alvo de forma mais próxima ao som de /a/ do que de /o/ indica que conseguiram estabelecer uma correspondência grafema-fonema em inglês diferente da esperada para o grafema "o" em português ou em espanhol. Com isso, pode-se dizer que os osciladores de F2 para a vogal da língua inglesa parecem carreados pelos osciladores da língua espanhola, promovendo uma maior associação entre as vogais /a/ e /a/ dessas línguas no eixo antero-posterior.

É preciso ressaltar, de forma geral, que se observou uma maior associação entre as vogais no eixo anteroposterior, o que parece indicar que há uma maior dificuldade por parte dos multilíngues de produzir as vogais das três línguas em espaços diferenciados. Outra conclusão importante a que se chega após refletir-se sobre as influências grafo-fônico-fonológicas encontradas entre as línguas é que essas influências parecem estar associadas a questões articulatórias e motoras. Assim, embora os multilíngues possam estar aptos a adquirir os novos sons das línguas estrangeiras, reconhecendo diferentes correspondências grafo-fônico-fonológicas entre as línguas, a produção oral é altamente influenciada pelos movimentos dos articuladores da fala. Nesse sentido, pode-se inferir que multilíngues que tenham aprendido suas línguas estrangeiras em idades mais avançadas e em contextos acadêmicos tenham mais dificuldades em controlar a produção das rotinas neuromotoras que estão acostumados a aplicar para a sua língua materna. Os espaços articulatórios já lapidados pelo uso constante da língua materna parecem agir como atratores, dificultando a produção das vogais das línguas menos proficientes. Deve-se chamar a atenção, portanto, para a relação estreita entre os conhecimentos grafêmicos, fonéticos e fonológicos durante a produção oral em uma determinada língua, já que a própria relação grafo-fônica pode levar à produção de determinados gestos no espaço articulatório já automatizado pelos atratores da L1.

\section{Conclusão}

Ao analisarem-se os dados de produção dos multilíngues que apontavam para a ocorrência de influências interlinguísticas, descobriu-se uma forte associação entre as vogais do português e do espanhol, assim como do português e do inglês.

Conclui-se, portanto, que a baixa associação entre as vogais da L2 e da L3 deve-se ao fato de os multilíngues não possuírem experiência de uso de suas línguas estrangeiras em contextos mais significativos, como os de imersão, o que poderia propiciar, por exemplo, que o conhecimento da língua espanhola, considerado altamente proficiente, gerasse padrões atratores mais fortes, que poderiam ter sido transferidos para uma língua menos proficiente, como a língua inglesa.

Outro fato a ser destacado é que as influências interlinguísticas entre as vogais foram notadas de forma parcial, ou seja, as vogais comparadas entre as línguas nunca foram associadas tanto em altura quanto em posição antero-posterior e duração. Por isso, em conformidade com Albano (2012), este trabalho destaca a possibilidade 
de sincronia ou sintonia incompleta entre os osciladores envolvidos para a produção da fala, visão amparada pela perspectiva dinâmica de conhecimento linguístico. É preciso, contudo, que mais estudos sobre a produção de vogais orais em multilíngues sejam realizados, para que se tenha mais conhecimento sobre a forma como se dá a influência grafo-fônico-fonológica em indivíduos que possuem conhecimento de mais de dois idiomas.

\section{Referências}

ALBANO, Eleonora. Uma introdução à dinâmica em fonologia, com foco nos trabalhos desta coletânea. In: ALBANO, E. (Org.). Revista da Abralin/Associação Brasileira de Linguística. Natal: UFRN, 2012. p. 1-30.

BARBOSA, Plínio. O Universal e o específico a língua em um modelo dinâmico de produção do ritmo (fonético e fonológico) da fala. In: CONGRESSO INTERNACIONAL DA ABRALIN, II, 2001, Fortaleza. Boletim da ABRALIN, v. 26, p. 89-91, 2001.

CENOZ, Jasone. Research on multilingual acquisition. In: CENOZ, J.; JESSNER, U. (Ed.). English in Europe. The acquisition of a third language. Clevedon: Multilingual Matters, 2000. p. 39-53.

DE BOT, Kess. The multilingual lexicon: modeling selection and control. International Journal of Multilingualism, v. 1, n. 1, p. 17-32, 2004

DE BOT, Kess; VERSPOOR, M.; LOWIE, W. Dynamical Systems Theory and Applied Linguistics: the ultimate 'so what'? International Journal of Applied Linguistics, v. 15, p. 116-118, 2005.

GOLDSTEIN, Louis; POUPLIER, Marianne; CHEN, Larissa; SALTZMAN, Eliot; BYRD, Dani. Dynamic action units slip in speech production errors. Cognition, 2007, v. 103, p. 386-412.
KELSO, J. Dynamic patterns: The self-Organization of Brain and Behavior (Complex Adaptative Systems). Massachusetts: MIT, 1995. 317 p.

LARSEN-FREEMAN, Diane. Chaos/complexity science and second language acquisition. Applied Linguistics, v. 18, p. 141-165, 1997.

MACWHINNEY. Brian. Language Emergence. In: BURMEISTER, P., PISKE, T.; RHODE, A. An integrated view of language development. Papers in honor of Henning Wode. Trier: Wissenchaftliche Verlag, 2002. p. 17-42.

RAPOSO DE MEDEIROS, Beatriz. Uma proposta sobre a coda do português brasileiro a partir da fonologia gestual, com foco especial na nasal. In: ALBANO, E. (Org.). Revista da ABRALIN, v. 11, n. 1, p. 89-138, 2012.

SILVA, Adelaide. As fronteiras entre fonética e fonologia e a alofonia dos róticos iniciais em PB: dados de dois informantes do sul do país. Tese (Doutorado) - Universidade Estadual de Campinas, São Paulo, 2002. 202 p.

VAN GELDER, Timothy; PORT, R. It's about time. In: R. PORT, R.; VAN GELDER, T. (Ed.). Mind as motion. Cambridge, MIT Press, 1995. p. 1-43.

ZIMMER, Márcia. A transferência do conhecimento fonéticofonológico do português brasileiro (L1) para o inglês (L2) na recodificação leitora: uma abordagem conexionista. Tese (Doutorado) - Pontifícia Universidade Católica do Rio Grande do Sul, Porto Alegre, 2004.

ZIMMER, Márcia; ALVES, Ubiratã. Uma visão dinâmica da produção da fala em L2: o caso da dessonorização terminal. In: ALBANO, E. Revista da ABRALIN, Associação Brasileira de Linguística, v. 11, p. 221-272, 2012.

Recebido: 15 de agosto de 2013

Aprovado: 29 de novembro de 2013

Contato: cintiablank@gmail.com marcia.zimmer@gmail.com

\section{ANEXo 1}

PALAVRAS UTILIZADAS NOS EXPERIMENTOS DE PRODUÇÃO ORAL

\section{Português}

Data, Bata, Pata, Paca, Pato Teta, Beco, Beba, Bebo, Dedo Teto, Pede, Beta, Peca, Queque Pica, Bica, Bico, Pipa, Quica Boca, Boba, Boto, Gota, Côco Copo, Bote, Toca, Pote, Bota Puta, Cuca, Cuba, Cuco, Tudo

\section{Espanhol}

Baca, Bazo, Caja, Dato, Pavo

Beca, Beso, Quepo, Quede, Ceta

Pido, Bibe, Pide, Silla, Pida

Coba, Poco, Codo, Pollo, Cosa

Duda, Cupe, Dudo, Cupo, Pudo

\author{
Inglês \\ Cock, Top, Pot, Pop, Cot \\ Bag, Back, Bad, Cat, Cap \\ Cub, Cut, Duck, Cup, But \\ Bed, Peck, Pet, Deck, Ted \\ Bead, Peat, Deed, Deep, Beat \\ Pit, Pig, Bib, Big, Tick \\ Dog, Bought, Talk, Caught, Taught \\ Coot, Poop, Goop, Boot, Coop \\ Cook, Took, Book, Good, Put
}

